\title{
Usefulness of transthoracic echocardiogram in management of cardiac involvement in large B-Cell lymphoma: a case report
}

\section{Utilità dell'ecocardiogramma nella gestione di un caso clinico di linfoma a grandi cellule di tipo B con coinvolgimento cardiaco}

\author{
Matteo Ruzzolini, Gaetano Luca Panetta, Antonietta Evangelista, \\ Carlo Peraldo Neja, Paolo Azzolini
}

\begin{abstract}
Usefulness of transthoracic echocardiogram in management of cardiac involvement in large B-Cell lymphoma: a case report. M. Ruzzolini, G.L. Panetta, A. Evangelista, C. Peraldo Neja, P. Azzolini.

Primary lymphoma often involve the heart, especially the right side. Prompt diagnosis is necessary to start the right therapy and decrease symptoms and death risk rate.
\end{abstract}

Transthoracic echocardiogram is the first line exam to perform when symptoms are suspicious of mediastinal mass.

Keywords: large B-cell lymphoma, transthoracic echocardiogram, pulmonary stenosis, pericardial effusion, cardiac imaging.

Monaldi Arch Chest Dis 2014; 82: 204-208.

San Giovanni Calibita - Fatebenefratelli Hospital, Rome, Italy.

Corresponding author: Dott. Paolo Azzolini; Ospedale San Giovanni Calibita - Fatebenefratelli, Isola Tiberina, via Ponte di Quattro Capi; I-00186Roma, Italy; E-mail address: paolo.azzolini@tin.it

\section{Introduction}

Cardiac involvement from a primary lymphoma is quite common, infact autoptic findings shows that incidence is between $8.7 \%$ and $27.2 \%$ [1-4]. Diagnosis is often difficult but improving in imaging techniques help us to detect those tumors [5-7]. In particular color-Doppler transthoracic echocardiography is a useful tool to analyze the mass by defining its relationship with the heart and the great vessels, to detect the presence of pericardial effusion and the involvement of pericardium. Furthermore, it is mandatory to estimate the presence and grading of the outflow tract obstruction that possibly determines significant stenosis. New chemotherapeutic agents have improved survival percentage of those patients, even the ones that present metastasis in different sites (including the heart). Cardiac initial presentation of a malignant lymphoma is very rare especially because symptoms are poor and not specific. In this report we present a case of 27-years-old female with large B cell lymphoma involving right ventricular outflow tract.

\section{Case Report}

A 27-years-old female presented to the Emergency Room (ER) with a few days history of mild dyspnea and exertional chest discomfort. On admission she referred fever one week before; no other relevant anamnestic data to report. A cardiology consulting to rule out myopericarditis was scheduled. Physical examination results were normal (pulse: $90 \mathrm{~b} / \mathrm{min}$; blood pressure: $120 / 70 \mathrm{mmHg}$ ) except for jugular swelling in sitting position and a 4/6 systolic murmur on pulmonary focus. Referred symptoms were mild degree dyspnea at rest and chest pain discomfort with normal breathing. Electrocardiogram (EKG) was normal. Clinical chemistry testing showed microcytic anaemia, and Troponin T-HS, Lactate Dehydrogenase (LDH), Erythrocyte Sedimentation Rate (ESR), C-reactive protein (CRP) and D-dimer were elevated (Tab. 1). A transthoracic Echocardiogram (TTE, Fig. 1) was performed in the ER revealing a mild circumferential pericardial effusion and a thoracic mass with pericardium infiltration signs determining $a b e x$ trinseco right ventricle outflow tract (RVOT) compression leading to a significant increased gradient (max $39 \mathrm{mmHg}$ ). To better define the mass and its relationship with the heart and other structures a total body angio-CT scan was performed (Fig. 2). At CT scan the mass showed irregular limits $(10 \mathrm{x}$ $9 \times 9 \mathrm{~cm}$ ) with a dysomogeneous structure including necrotic tissue areas located in the anterosuperior mediastinum. Involvement of RVOT, pulmonary trunk was confirmed as well as the pericardial infiltration and effusion. There were also unveiled three more masses with the same structure, two of them $(40 \times 44 \mathrm{~mm}$ and $39 \times 42 \mathrm{~mm})$ at the level of greater omentum determining a compression at hepatic level and another one $(29 \times 32 \mathrm{~mm})$ at the splenic hilum level, just below the splenic vein. Subsequently a CT guided biopsy was performed. A cortisone (Dexamethasone) therapy was started leading to prompt symptoms decreasing. 


\begin{tabular}{|c|c|c|}
\hline \multirow[t]{6}{*}{ Peripheral Blood } & White blood cell & 7.3 tho/ $\mu \mathrm{L}$ \\
\hline & Red blood cell & $4.2 \mathrm{mil} / \mu \mathrm{L}$ \\
\hline & Hematocrit & $32.7 \%$ \\
\hline & Hemoglobin & $9.9 \mathrm{~g} / \mathrm{dl}$ \\
\hline & $\mathrm{MCV}$ & $77.7 \mathrm{fL}$ \\
\hline & Platelet & 379 tho/ $\mu \mathrm{L}$ \\
\hline \multirow[t]{3}{*}{ Coagulation } & INR & 1.18 \\
\hline & PTT Ratio & 1.12 \\
\hline & D-Dimer & $1074 \mathrm{ng} / \mathrm{mL}$ \\
\hline \multirow[t]{14}{*}{ Blood Chemistry } & Glycemia & 93 mg/dL \\
\hline & Urea & $23 \mathrm{mg} / \mathrm{dL}$ \\
\hline & Creatinine & $0.7 \mathrm{mg} / \mathrm{dL}$ \\
\hline & $\mathrm{Na}$ & $148 \mathrm{mmol} / \mathrm{L}$ \\
\hline & $\mathrm{K}$ & $4.5 \mathrm{mmol} / \mathrm{L}$ \\
\hline & AST & $18 \mathrm{U} / \mathrm{L}$ \\
\hline & ALT & $16 \mathrm{U} / \mathrm{L}$ \\
\hline & Troponin T-HS & $0.020 \mathrm{ng} / \mathrm{mL}$ \\
\hline & Myoglobin & $21 \mathrm{ng} / \mathrm{mL}$ \\
\hline & CK-MB & $0.7 \mathrm{ng} / \mathrm{mL}$ \\
\hline & $\mathrm{CPK}$ & $101 \mathrm{U} / \mathrm{L}$ \\
\hline & LDH & $920 \mathrm{U} / \mathrm{L}$ \\
\hline & ESR & $117 \mathrm{~mm} \mathrm{1h}$ \\
\hline & CRP & $5,924 \mathrm{mg} / \mathrm{dL}$ \\
\hline
\end{tabular}
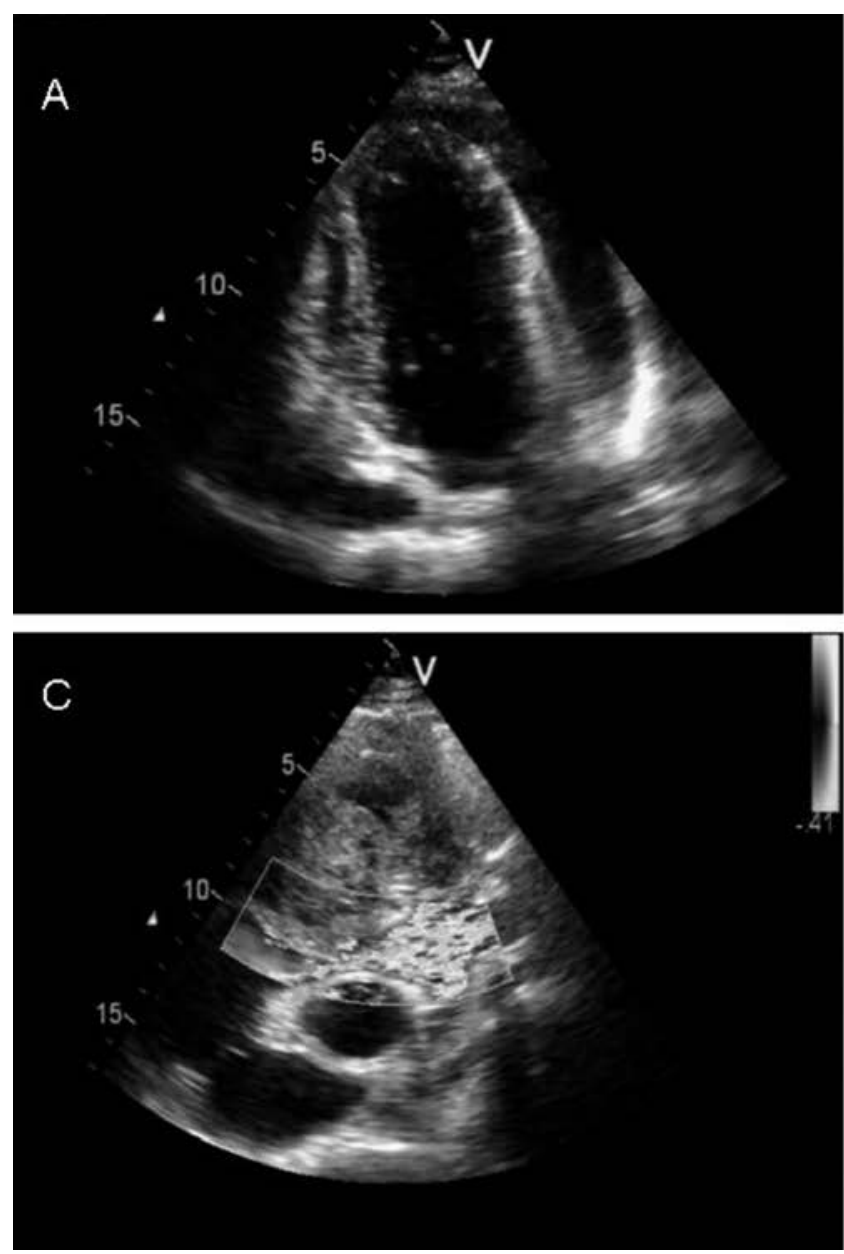

Thus, a new transthoracic echocardiogram (Fig. 3) was performed showing reduction of RVOT compression including pericardial effusion. Based on immunohistopathologic findings diagnosis of primary mediastinal large B-cells lymphoma was made and chemotherapy was started following CHOP protocol (Cyclophosphamide, Doxorubicin, Vincristine and Prednisone).

After one month a new transthoracic echocardiogram (Fig. 4) revealed remarkable mass reduction and almost completely disappearance of the pulmonary trunk compression (maximum pressure gradient: $6 \mathrm{mmHg}$ ).

\section{Discussion}

Lymphoma deposits represent $13.6 \%$ of metastatic tumors to the heart [2].

Almost one third of extrinsic RVOT obstruction is caused by lymphomas [8-9]. Diagnosis of malignant lymphoma metastasizing to the heart is quite common, only in post mortem settings [10]. However, an ante mortem diagnosis of secondary involvement of the heart by malignant lymphoma is not only difficult but rare. Extremely unusual is a first lymphoma diagnosis based on echocardiographic finding of a mediastinal mass involving the heart. As imaging modalities and treatment options for lymphoma improve, more unusual disease presentations may be observed more frequently.
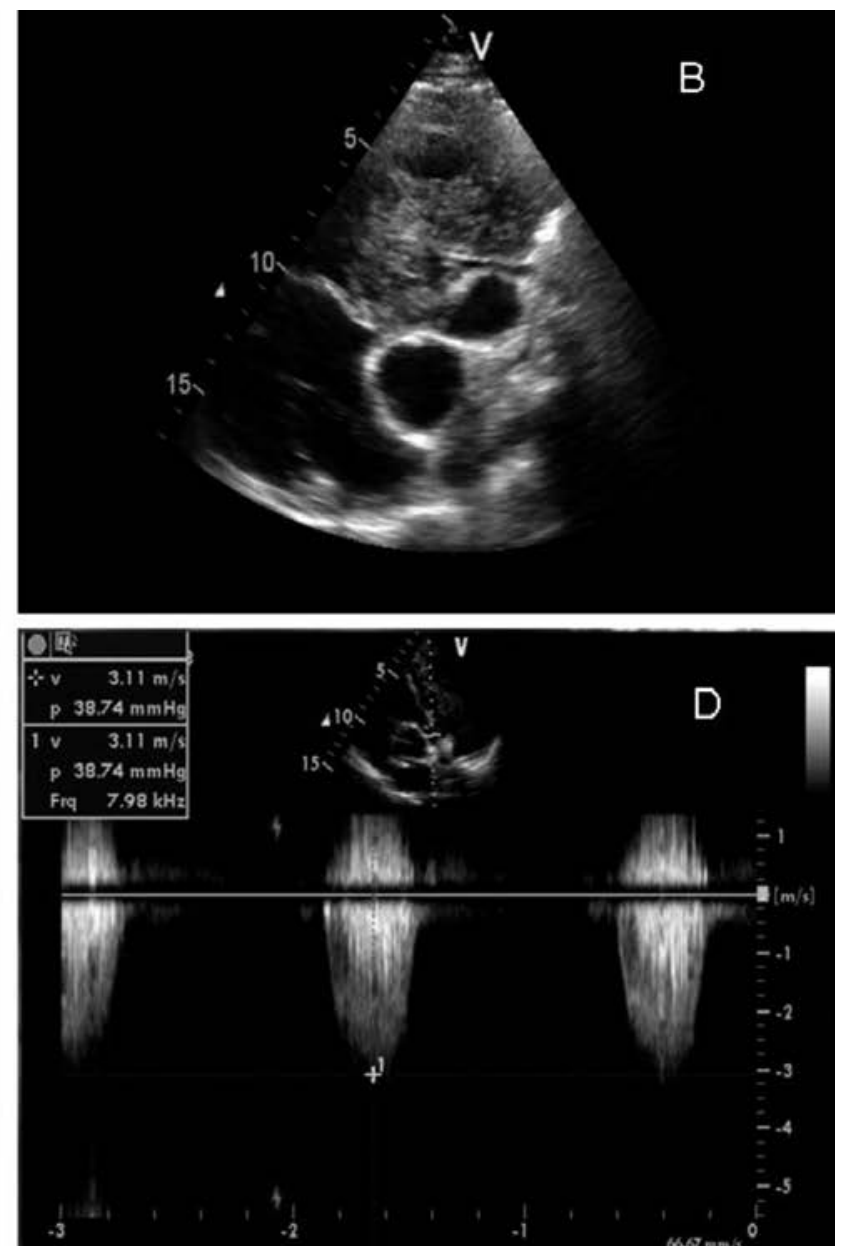

Figure 1. - E.R. echocardiogram A) 4 chambers view with evidence of global pericardial effusion. B, C, D) Short axis view focused on RVOT shows the ab extrinseco obstruction by the thoracic mass, B-mode, colour and doppler images. 

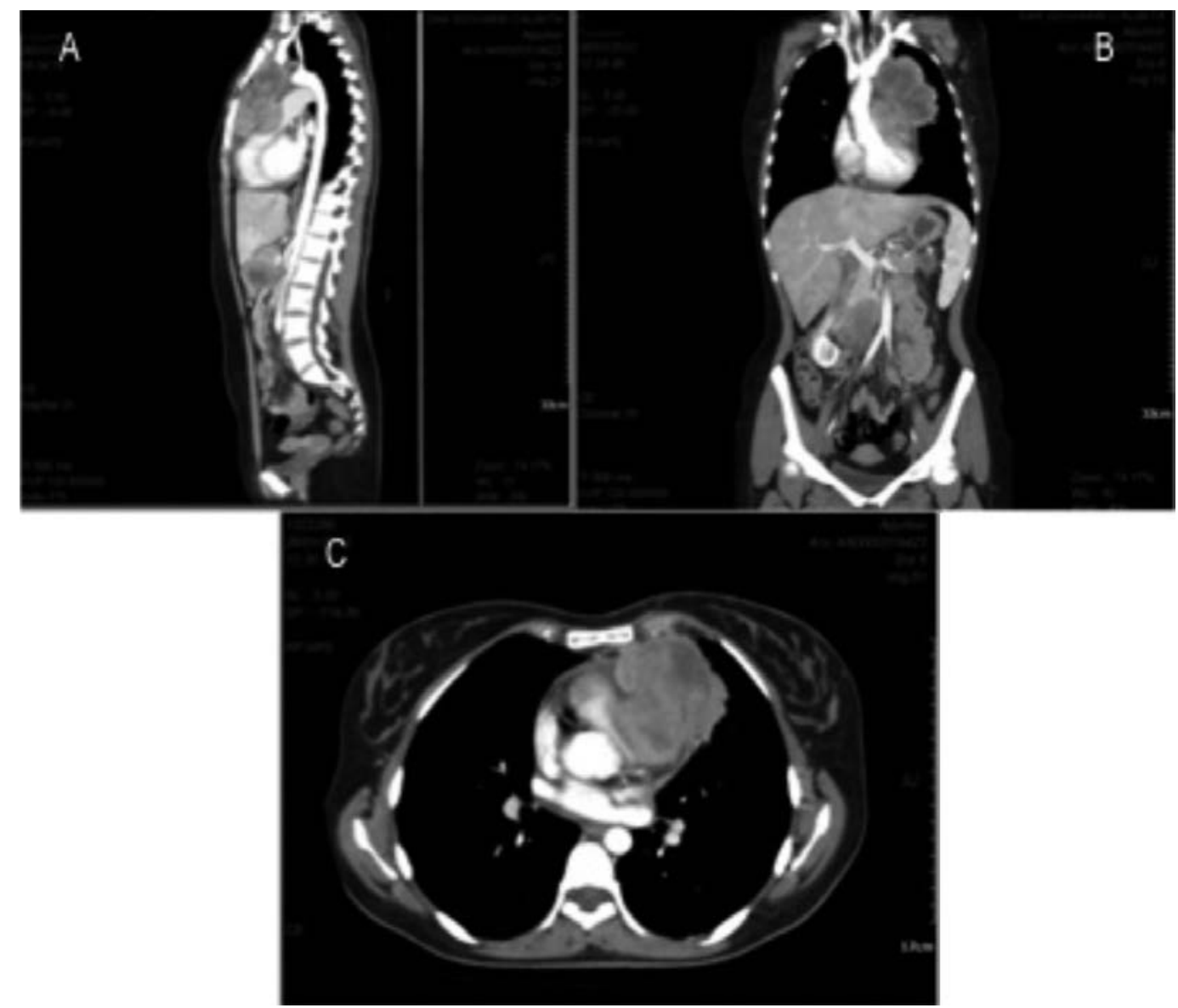

Figure 2. - TC images: sagittal (A), coronal (B) and axial (C) scans show the thoracic mass relation with the heart., particularly with the RVOT.
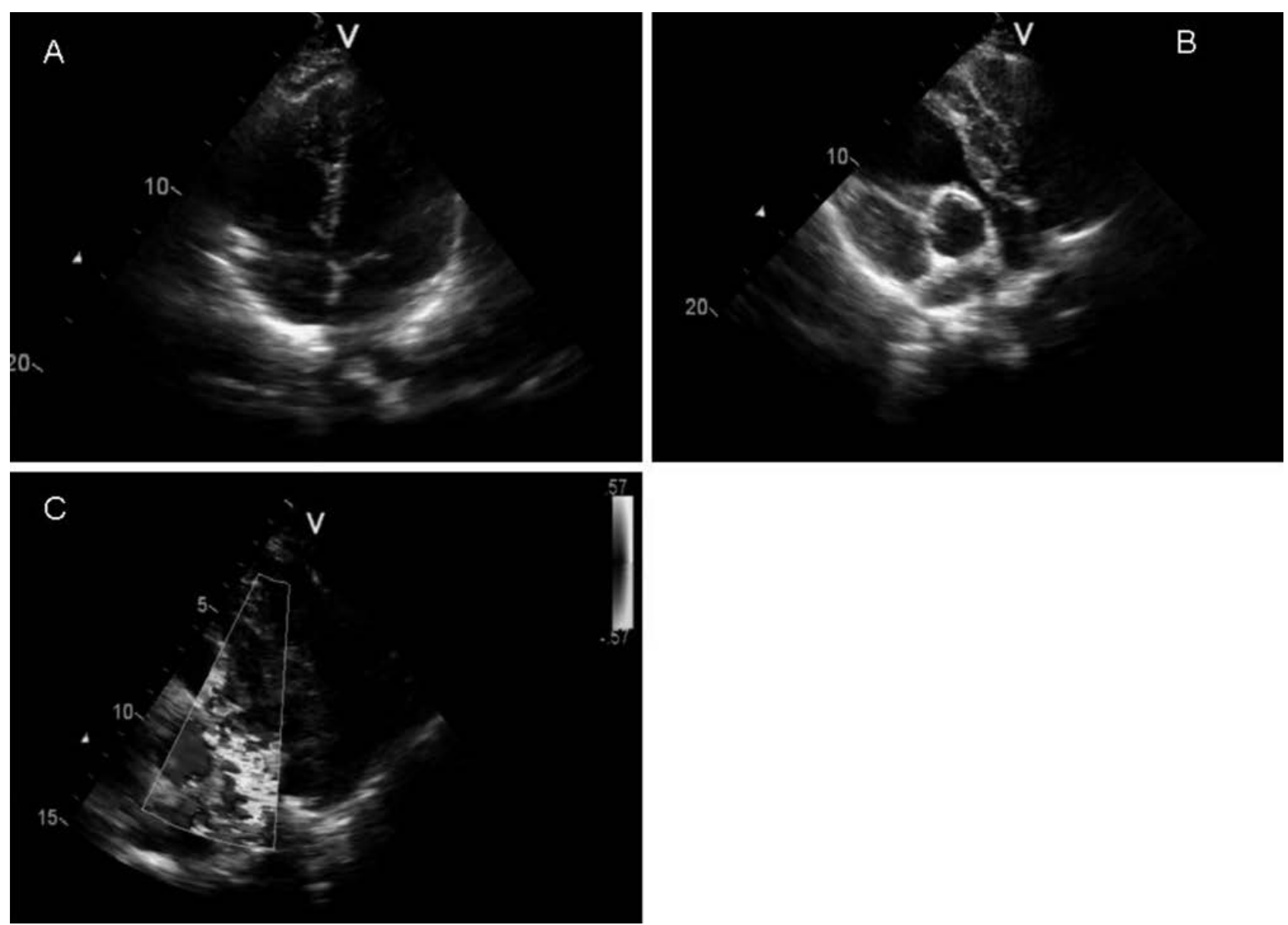

Figure 3. - Control echocardiogram exam shows the reduction of pericaldial effusion (A), grade of mass compression on RVOT (B), visible also with the color (C). 

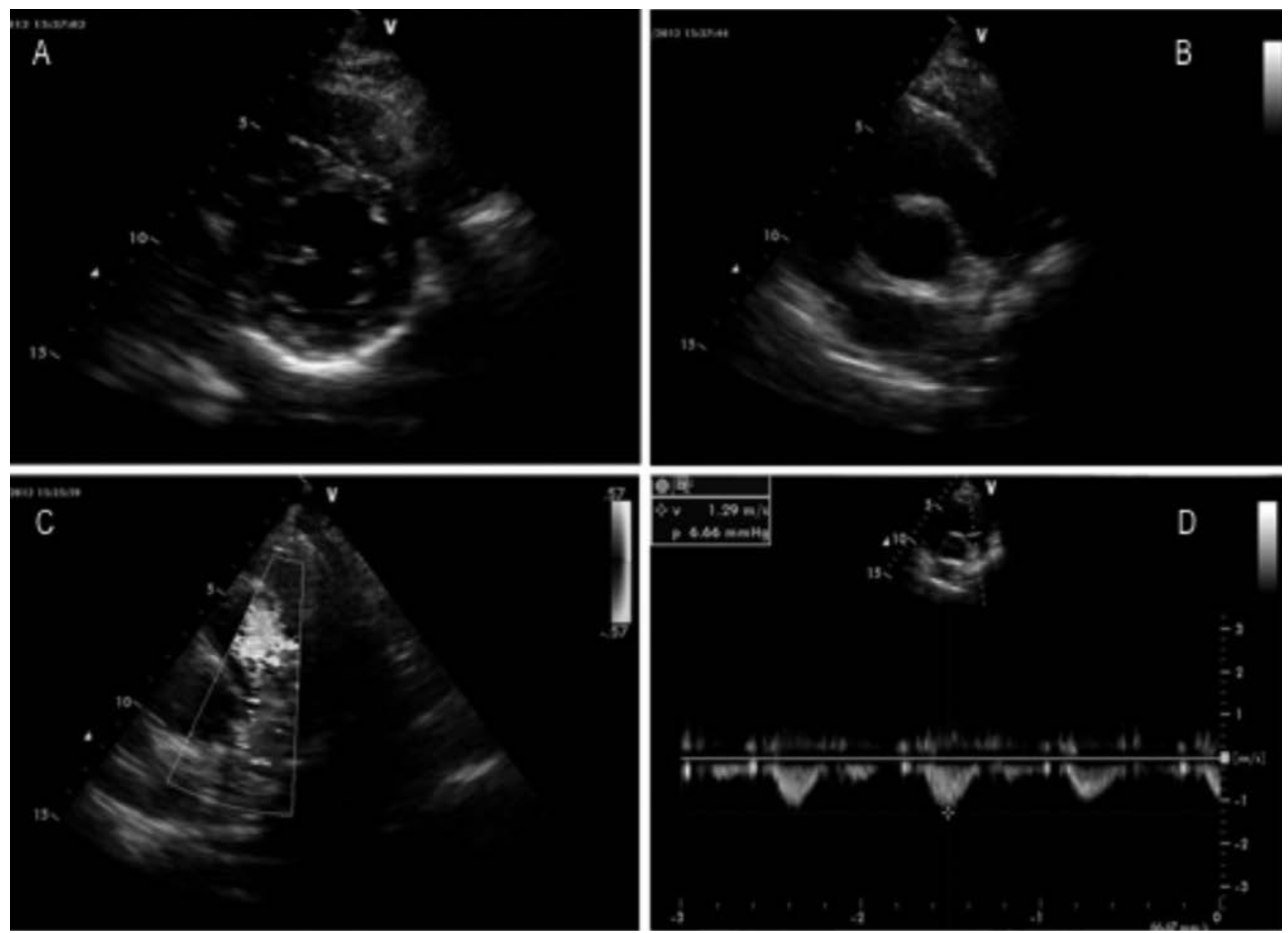

Figure 4. - One month echocardiogram follow up. A) minimal pericardial effusion B,C,D) Images of further reduction of mass impact on the heart: B-mode, color e doppler images.

Due to heterogeneity of clinical presentation diagnosis of those tumors is often delayed and it is related to poor outcomes. Among all the symptoms, chest pain and dyspnoea are the most common and they were present also in our case. EKG is usually normal in those patients even if one case of right axis deviation was reported [8]. In our case symptoms and laboratory results lead us to perform a transthoracic echocardiogram that showed a mediastinal mass determining RVOT compression and pericardial effusion. Previous case reports described the importance of TTE as first line imaging exam $[9,11-14]$ to address to the correct diagnosis. Sometimes due to the technique limitations [15] or to better distinguish between clot and tumor Transesophageal Echocardiogram (TEE) is necessary [16]. However more detailed techniques as angio-CT scan $[9,11,13]$ or Magnetic Resonance Imaging $[4,17]$ are mandatory to describe the mass and its relationship with the closer structures. Positron Emission Tomography (PET) has been showed to be a considerable technique to detect unapparent cardiac involvement [11, 18-19]. In this particular case TTE was a very crucial exam not only because it led us to the diagnosis of mediastinal mass (subsequently confirmed by angio-CT scan) but also because we were able to promptly start a therapy that improved symptoms. Moreover we could schedule follow up exams to evidence haemodynamic im- provement of RVOT compression and pericardial effusion regression.

\section{Conclusion}

Transthoracic Echocardiography is the first line imaging exam to perform when symptoms are possibly related to a mediastinal mass. This simple and feasible technique is also useful to schedule follow up exams after the beginning of therapy as to analyze changes in haemodynamics.

\section{References}

1. Tanaka T, Sato T, Akifuji Y et al. Aggressive nonHodgkin's lymphoma with massive involvement of the right ventricle. Intern Med 1996; 10: 826-830.

2. Rosenberg SA, Diamond HD, Jaslowitz B et al. Lymphosarcoma: A review of 1269 cases. Medicine 1961; 40: 31-84.

3. Roberts WC, Glancy DL, DeVita VT Jr. Heart in malignant lymphoma (Hodgkin's disease, lymphosarcoma, reticulum cell sarcoma and mycosis fungoides). A study of 196 autopsy cases. Am J Cardiol 1968; 1: 85-107.

4. Ban-Hoefen M, Zeglin MA, Bisognano JD. Diffuse large B cell lymphoma presenting as a cardiac mass and odynophagia. Cardiol J 2008; 15(5): 471-4.

5. Terasawa A, Sugihara S, Itoh K et al. Malignant lymphoma presenting as a cardiac tumor. Virchows Arch A Pathol Anat Histopathol 1991; 3: 183-189.

6. Zuppiroli A, Cecchi F, Ciaccheri $\mathrm{M}$ et al. Two-dimensional echocardiographic findings in a case of massive 
cardiac involvement by malignant lymphoma. Acta Cardiol 1985; 40: 485-492.

7. Saito T, Tamaru J, Kayao J et al. Cytomorphologic diagnosis of malignant lymphoma arising in the heart: A case report. Acta Cytol 2001; 6: 1043-1048.

8. Putterman C, Gilon D, Uretzki G, et al. Right ventricular outflow tract obstruction due to extrinsic compression by non-Hodgkin's lymphoma: Importance of echocardiographic diagnosis and follow up. Leuk Lymphoma 1992; 7: 211-215.

9. Ren J, Rich MW, Makan M. Right ventricular outflow tract obstruction by lymphoma: case series and review of the literature. Echocardiography 2011 Nov; 28(10): 1164-7.

10. Lam KY, Dickens P, Chan AC. Tumors of the heart. A 20-year experience with a review of 12,485 consecutive autopsies. Arch Pathol Lab Med 1993; 117: 1027-31.

11. O'Mahony D, Peikarz RL, Bandettini WP, Arai AE, Wilson WH, Bates SE. Cardiac involvement with lymphoma: a review of the literature. Clin Lymphoma Myeloma 2008 Aug; 8(4): 249-52.

12. Kaderli AA, Baran I, Aydin O, Bicer M, Akpinar T, Ozkalemkas F, Yesilbursa D, Gullulu S. Diffuse involvement of the heart and great vessels in primary cardiac lymphoma. Eur J Echocardiogr 2010 Jan; 11(1): 74-6.
13. Konstandin MH, Korosoglou G, Hosch W, Hardt SE, Katus HA, Mereles D. Severe right ventricular outflow tract obstruction caused by non-hodgkin lymphoma: complete regression after one course of bendamustine/rituximab therapy. J Am Soc Echocardiogr. 2011 Jul; 24(7): 818.

14. Badheka A, Marzouka GR, Patel NJ, Esterson J, Sequeira RF. Pseudo-pulmonic stenosis in non-hodgkin's large Bcell lymphoma. Echocardiography 2012 Aug; 29(7): E166-8.

15. Majano-Lainez RA. Cardiac tumors: a current clinical and pathological perspective. Crit Rev Oncog 1997; 8: 293-303.

16. Meng Q, Lai H, Lima J, et al. Echocardiographic and pathologic characteristics of primary cardiac tumors: a study of 149 cases. Int J Cardiol 2002; 84: 69-75.

17. Maria MI, Squire SW, Kudithipudi V, et al: Cardiac MRI is complementary to echocardiography in the assessment of cardiac masses. Echocardiography 2007; 24: 286-300.

18. Nguyen JD, Carrasquillo JA, Little RF, et al. Fluorodeoxyglucose positron emission tomography in the presence of cardiac metastases. Clin Nucl Med 2003; 28: 979-80.

19. Romer W, Garbrecht M, Fuchs C, et al. Images in cardiovascular medicine. Metabolic imaging identifies nonHodgkin's lymphoma infiltrating heart. Circulation 1998; 97: 2577-8. 